\title{
Low-diversity fungal assemblage in an Antarctic Dry Valleys soil
}

\author{
Subramanya Rao $\cdot$ Yuki Chan • Donnabella C. Lacap • \\ Kevin D. Hyde • Stephen B. Pointing • \\ Roberta L. Farrell
}

Received: 22 July 2011/Revised: 31 August 2011/Accepted: 1 September 2011/Published online: 25 September 2011

(C) The Author(s) 2011. This article is published with open access at Springerlink.com

\begin{abstract}
The McMurdo Dry Valleys of Antarctica present extreme environmental challenges. Life is restricted to patchy occurrence of lichens, mosses and invertebrates, plus soil microbial communities. Fungi have been described in lichen symbioses but relatively little is known about the occurrence of free-living soil fungi in the Dry Valleys. A challenge in estimating fungal species richness has been the extent to which estimates based on either cultivation or environmental DNA reflect the active assemblage in cold-arid soils. Here, we describe analysis for inland Dry Valleys soil of environmental DNA and RNA (cDNA) to infer total and putative metabolically active assemblages, respectively, plus cultivation approaches using a variety of laboratory growth conditions. Environmental sequences indicated a highly restricted assemblage of just seven phylotypes that affiliated phylogenetically within two known genera, Helicodendron and Zalerion, plus previously unidentified fungal phylotypes. None of the commonly encountered molds and mitosporic genera recorded from maritime Antarctic locations were
\end{abstract}

S. Rao · Y. Chan · D. C. Lacap · S. B. Pointing $(\bowtie)$

School of Biological Sciences, The University of Hong Kong, Pokfulam Road, Hong Kong SAR, China

e-mail: pointing@hku.hk

\section{K. D. Hyde}

School of Science, Mae Fah Luang University,

Chiang Rai 57100, Thailand

K. D. Hyde

Botany and Microbiology Department, College of Science,

King Saud University, P.O. Box: 2455,

Riyadh 1145, Saudi Arabia

R. L. Farrell

Department of Biological Sciences, The University of Waikato, Hamilton, New Zealand encountered. A striking difference was observed in the frequency of recovery for phylotypes between libraries. This suggests that both species richness and beta diversity estimates based on DNA libraries have the potential to misinform putatively active assemblages. Cultivation yielded a cold-tolerant Zalerion strain that affiliated with DNA and RNA library clones, and a psychrotrophic yeast (Debaryomyces hansenii), which was not detected using either culture-independent approach.

Keywords Antarctica D Debaryomyces $\cdot$ Helicodendron . Soil fungi $\cdot$ Zalerion

\section{Introduction}

The continent of Antarctica poses challenges to all forms of life in terms of extreme environmental stress and geographical isolation of habitats. The McMurdo Dry Valleys in Eastern Antarctica are acknowledged as the coldest, driest desert on Earth (Wynn-Wiliams 1990). Ice-free terrain in the floor of the Dry Valleys is characterized by desert pavement with pebbles and rocks embedded in a mineral soil. Significant heterogeneity in climate exists between and within valley locations; the higher altitude inland valleys generally impose more severe limitations on biological activity (Doran et al. 2002). While mosses and a limited range of invertebrates are encountered in wetter locations (Convey et al. 2009), the most arid inland valleys may support exclusively microbial communities (Cary et al. 2010).

Lichens (epilithic and endolithic) colonize rock substrates and have been studied extensively (Friedmann 1982), but conversely relatively little is known of the biodiversity and ecology of free-living fungi in Antarctic Dry Valleys soil. A relatively large inventory of fungal 
biodiversity exists for maritime Antarctic and sub-Antarctic soils (Vishniac 1996). Onofri et al. (2004) reported that in Antarctica, $0.6 \%$ of the known fungal species were water molds (kingdom Chromista) and $99.4 \%$ were composed of true fungi including yeasts (unicellular organisms) and filamentous fungi from the phyla Chytridomycota, Zygomycota, Ascomycota and Basidiomycota. A key study that included Dry Valleys sites revealed that some locations (e.g., Mt Fleming, Allan Hills) supported cultivable freeliving soil fungi (Arenz et al. 2006) including Cryptococcus antarcticus, C. friedmannii, C. vishniacii and Candida parapsilosis. They detected six additional yeast species and eight additional filamentous fungi using DGGE-based analysis of environmental DNA. Conversely in extreme inland Dry Valleys soil at McKelvey Valley, no fungal signatures were recorded using molecular approaches (Pointing et al. 2009). Other more benign ice-free locations in Dronning Maud Land (Singh et al. 2006) revealed a yeast (Torulopsis psychrophila) plus several isolates of Acremonium, Cladosporium, Fusarium, Penicillium and Trichoderma. Polyphasic studies of maritime Antarctic soils have shown they support Cladosporium, Cryptococcus, Geomyces and other molds, plus a basidiomycete yeast genus Rhodotorula (Malosso et al. 2006).

Previous studies have employed cultivation and environmental DNA approaches but these approaches do not reveal whether the fungi were active in situ. A key issue in fungal and Antarctic microbial ecology is resolving what is active rather than simply what signatures are recoverable, particularly in light of concerns over potential cryopreservation of DNA in Antarctic soils. The fungi are potentially an important indicator of trophic complexity among microbial communities and furthermore have important implications for understanding eukaryotic survival at the cold-arid limit for life, potential for soil conditioning via long-term colonization and the implications of climate change on this process.

In a recent study of McKelvey Valley, a high lake-free valley with saline soils, we showed that on a landscape scale, surface soils did not support detectable levels of eukaryotic microorganisms, which were restricted to lithic refugia as hypoliths, chasmoendoliths, or cryptoendoliths (Pointing et al. 2009). We have recently analyzed additional samples collected from this valley near a large persistent snowdrift, where we reasoned a long-term wetter environment (due to periodic snowmelt) that may have allowed greater biocomplexity to develop in the soil. Here, we report a polyphasic study to characterize cultivable, environmental DNA and environmental RNA (cDNA) signatures of yeasts and filamentous fungi from this location. Our rationale was not only to detect latent resting structures but also to gain some insight into potentially metabolically active fungal taxa. While this likely represents an opportunistic fungal assemblage, the data provide useful further insight into the heterogeneity of Dry Valleys soil biota, cold-arid limit for fungal colonization and an indication of how environmental change in Dry Valley systems may impact eukaryotic microbial biodiversity.

\section{Materials and methods}

Soil collection and analysis

The sampling site was in McKelvey Valley, McMurdo Dry Valleys, Antarctica $\left(77^{\circ} 26^{\prime} \mathrm{S}, 161^{\circ} 33^{\prime} \mathrm{E}\right)$. Soil was collected as part of Antarctica New Zealand Event K021B. Soil samples that were collected from a patch of visibly moist soil downhill form a persistent snowdrift that was releasing melt water. Soil was aseptically recovered from 2 to $5 \mathrm{~cm}$ below the soil surface and stored in RNA later (Ambion) for nucleic acid preservation at ambient temperatures until processed (approx. 1 week) or frozen at $-20^{\circ} \mathrm{C}$ for samples destined for cultivation. An initial assessment of fungal diversity in three soil samples using terminal restriction fragment length polymorphism (TRFLP) signatures of the ITS region revealed no significant difference between soil assemblages; thus, a single soil sample was selected for detailed study. A total of 10 chemical variables were assessed in the soil analysis (soluble salts, calcium, iron, magnesium, phosphorous, potassium, sodium, $\mathrm{pH}$, total carbon and total nitrogen), and the results are shown in Table 1. Ambient temperatures remained below freezing throughout the sampling period in January 2008, although solar heating of ground created isolated patches of snowmelt. Long-term climate data are available at the following link: http://www.scar.org. Moisture content and total organic content in soils and rocks were measured gravimetrically after heating to 100 and $450^{\circ} \mathrm{C}$, respectively. Soluble salts and $\mathrm{pH}$ were measured by potentiometric determination. Total carbon and nitrogen were determined using a thermal conductivity

Table 1 Physico-chemical properties of soil from which fungal diversity was estimated

\begin{tabular}{ll}
\hline Soluble salts $(\mathrm{g} / 100 \mathrm{~g})$ & 0.34 \\
$\mathrm{Ca}(\mathrm{mg} / \mathrm{kg})$ & 17,000 \\
$\mathrm{Fe}(\mathrm{mg} / \mathrm{kg})$ & 21,000 \\
$\mathrm{Mg}(\mathrm{mg} / \mathrm{kg})$ & 6,200 \\
$\mathrm{P}(\mathrm{mg} / \mathrm{kg})$ & 350 \\
$\mathrm{~K}(\mathrm{mg} / \mathrm{kg})$ & 1,400 \\
$\mathrm{Na}(\mathrm{mg} / \mathrm{kg})$ & 2,900 \\
$\mathrm{pH}$ & 8.2 \\
Total organic carbon $(\mathrm{g} / 100 \mathrm{~g})$ & 0.11 \\
Total nitrogen $(\mathrm{g} / 100 \mathrm{~g})$ & 0.15 \\
\hline
\end{tabular}


detector at $900^{\circ} \mathrm{C}$. All elemental tests were conducted after air-drying and nitric/hydrochloric acid digestion using ICPMS according to US EPA 200.2.

\section{Recovery of environmental RNA, DNA and PCR amplification}

Total RNA was extracted from $50 \mathrm{mg}$ of soil using TRI reagent (Molecular Research Centre, Inc.), quantified by spectrophotometry (Smartspec-Plus, Bio-Rad, California). The cDNA was synthesized using $1-2 \mu \mathrm{l}(50-100 \mathrm{ng})$ of RNA, $0.5 \mu \mathrm{g}$ of oligo $(\mathrm{dT})_{15}$ and the ImProm-II ${ }^{\mathrm{TM}}$ Reverse transcriptase kit according to manufacturer's instructions (Promega, USA). Total DNA was extracted from $50 \mathrm{mg}$ of soil using PowerSoil ${ }^{\mathrm{TM}}$ DNA isolation kit following the manufacturer's protocol (MO BIO Laboratories Inc., Carlsbad, CA, USA). DNA amplification was performed by PCR. The ITS5 and ITS4 (White et al. 1990) primer pairs were used to amplify ITS rRNA gene region. The temperature profile included an initial denaturation step at $95^{\circ} \mathrm{C}$ for $1 \mathrm{~min}$, a primer annealing step at $52^{\circ} \mathrm{C}$ for $50 \mathrm{~s}$ and an extension step at $72^{\circ} \mathrm{C}$ for $1 \mathrm{~min}$, followed by a final step of $72^{\circ} \mathrm{C}$ for $10 \mathrm{~min}$ ( 30 cycles in total). The presence of PCR products was confirmed by electrophoresis in $1 \%$ agarose gels. Purification of PCR product was carried out using GFX ${ }^{\mathrm{TM}}$ PCR DNA and gel band purification kit (GE Healthcare, United Kingdom).

\section{Clone library construction and sequencing}

Clone libraries were constructed for RNA (cDNA) and DNA using the TOPO TA Cloning ${ }^{\circledR}$ kit (Invitrogen). Phylotype sorting was performed using restriction fragment length polymorphism (RFLP) (using CfoI and HinfI) before automated sequencing (3730 Genetic Analyzer, Applied Biosystem). Phylotypes were delineated on the basis of $97 \%$ sequence similarity using the freeware DOTUR (Schloss and Handelsman 2005). Sampling effort was assessed by the calculation of rarefaction curves and estimates of the OTU richness from clone libraries were made using Chao1 with Estimate S (Cowell 2005). Approximate phylogenetic affiliations were determined by BLAST searches of the NCBI GenBank database (http://www.ncbi.nlm.nic.gov/).

Sequence alignment and phylogenetic analysis

Sequences obtained from the respective RNA and DNA were used to create multiple alignments with reference to selected GenBank sequences using ClustalXv.1.81 (Thompson et al. 1997). Maximum-likelihood analysis was performed using PAUP* 4.0b8 (Swofford 2001). Bayesian posterior probabilities and bootstrap values $(1,000$ replications) are shown for branch nodes supported by more than $50 \%$ of the trees. All sequences have been deposited in the NCBI GenBank database under accession numbers (JF792842-JF792857).

\section{Cultivation of Antarctic soil fungi}

Isolation of Antarctic soil fungi was carried out by diluting $1 \mathrm{~g}$ of soil in $100 \mathrm{ml}$ of sterile water (supplemented with 0 , 1.5 or $3 \% \mathrm{w} / \mathrm{v} \mathrm{NaCl}$ ). Aliquots of $0.5 \mathrm{ml}$ were spreadplated onto 2\% Difco MEA (malt extract agar), PDA (potato dextrose agar) and SDA (Sabouraud-DextroseAgar). Direct soil plating was also carried out, where $0.5 \mathrm{~g}$ of soil was directly introduced to agar surfaces. The plates were sealed and incubated at $4^{\circ}, 10^{\circ}$ or $20^{\circ} \mathrm{C}$ for 45 days. For each treatment, one uninoculated control plate was also incubated to allow the detection of putative contaminants.

Phylogenetic analysis of cultivated strains

DNA recovery from cultivated fungi was achieved by lysis in CTAB with lysozyme and RNAse, followed by phenol/ chloroform extraction at $60^{\circ} \mathrm{C}$. DNA was checked for quality by electrophoresis in $1 \%$ agarose gels and quantified by spectrophotometry. PCR and sequencing and phylogenetic analysis were then performed as described above.

\section{Results}

Chemical analysis of soil revealed low levels of organic carbon and nitrogen, neutral $\mathrm{pH}$, moderate salinity and non-inhibitory levels of trace metals (Table 1). At the time of sampling, soil contained approximately $2 \% \mathrm{w} / \mathrm{v}$ moisture. We did not conduct plate counts for fungi since they are unlikely to reflect actual fungal abundance in soils; rather, we adopted a combined molecular and cultivation approach to estimate fungal diversity in soil.

The cultivation approach employed a variety of growth media (nutrient source and concentration, salinity as a function of sodium chloride $[\mathrm{NaCl}]$ concentration) and varied cultivation temperatures. The results revealed that only two fungal taxa were cultivable even after extended incubation periods of over 3 months and they were both ascomycetes, comprising Debaryomyces hansenii, a yeast; and Zalerion varium (identical to phylotypes recovered in DNA and cDNA libraries), a filamentous fungus usually associated with marine environments. Both strains displayed a preference for $10 \times$ diluted MEA or PDA and did not grow on SDA growth medium. Strains displayed growth at $4^{\circ} \mathrm{C}$, with an optimal rate of radial growth at $10^{\circ} \mathrm{C}$. Both strains were also capable of growth at reduced rates (as measured qualitatively by observing growth of hyphae on agar growth medium) at up to $20^{\circ} \mathrm{C}$. We therefore 
Fig. 1 Relative abundance of fungal phylotypes from DNA and RNA (cDNA) clone libraries of fungal ITS loci, from moisture-impacted soil of McKelvey Valley, McMurdo Dry Valleys, Antarctica

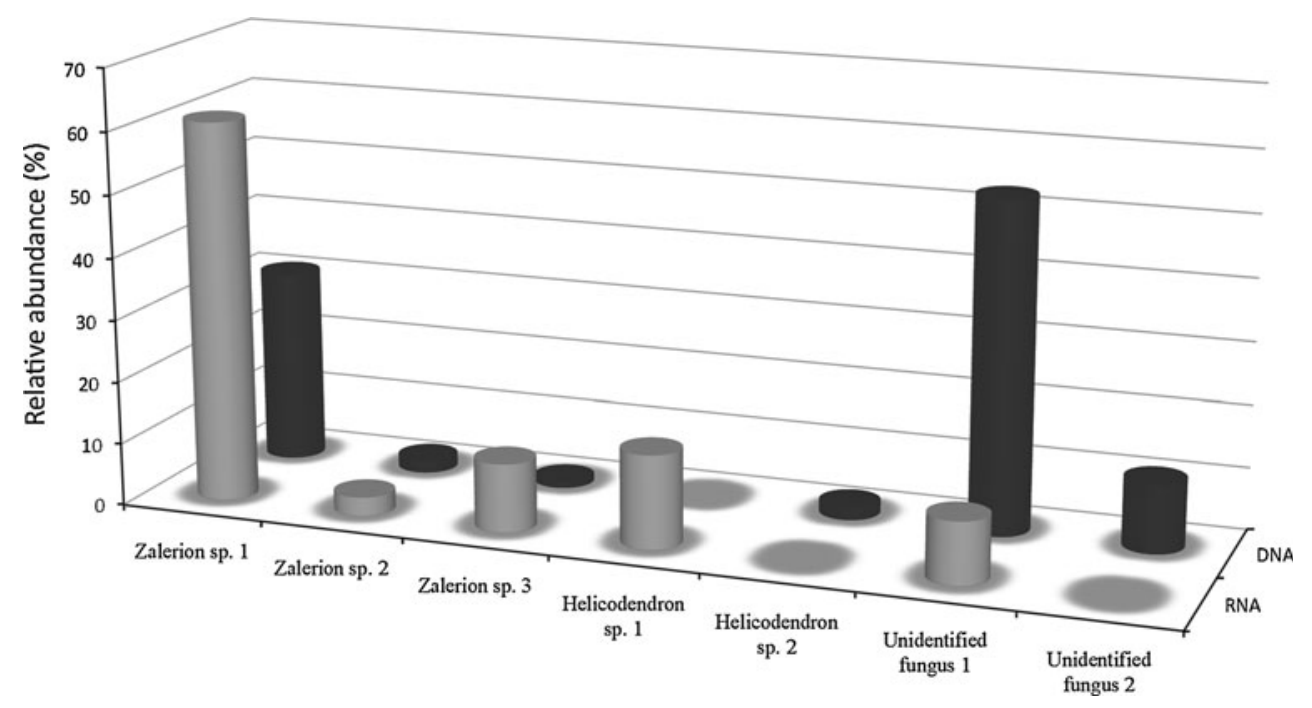

concluded that these represent cold-tolerant (psychrotrophic) rather than psychrophilic variants, according to the definitions of Gerday et al. (1997). The Debaryomyces and Zalerion strains displayed optimal radial growth on agar not supplemented with $\mathrm{NaCl}$, although both strains displayed growth at reduced rates in media supplemented with up to $3 \% \mathrm{w} / \mathrm{v} \mathrm{NaCl}$. No growth of common molds or other ascomycete or basidiomycete taxa was recorded for soilinoculated plates during our isolation procedure.

Our DNA-based analysis of the soil sample by sequencing of a clone library $(n=100)$ yielded 6 phylotypes as delineated by $97 \%$ sequence similarity (Fig. 1). A BLAST search of the NCBI GenBank database indicated over almost $70 \%$ of these affiliated with previously unidentified ascomycetous fungal taxa, while a Zalerion phylotype accounted for approximately one-third of phylotypes. Other Zalerion and Helicodendron phylotypes were recovered with low frequency. The second library was constructed from cDNA synthesized from environmental RNA $(n=100)$. This revealed 5 phylotypes using the same identification criteria as the DNA library (Fig. 1). A BLAST search indicated that this library was dominated by Zalerion phylotypes, with low abundance of Helicodendron-like and unidentified phylotypes. The frequency of recovery between the two libraries was markedly different, and three phylotypes were recovered in one but not both libraries. No yeast phylotypes were recovered from either library, despite the primer sites matching known psychrotrophic yeast rRNA genes in the NCBI GenBank database and successful amplification in our study of the cultivated Debaromyces hansenii strains from our study site using the same PCR primers. Estimates of sampling sufficiency for DNA and RNA libraries indicated that while the RNA library was sampled with an estimated $100 \%$ coverage, the DNA library sampling curve had not reached asymptote (Fig. 2).

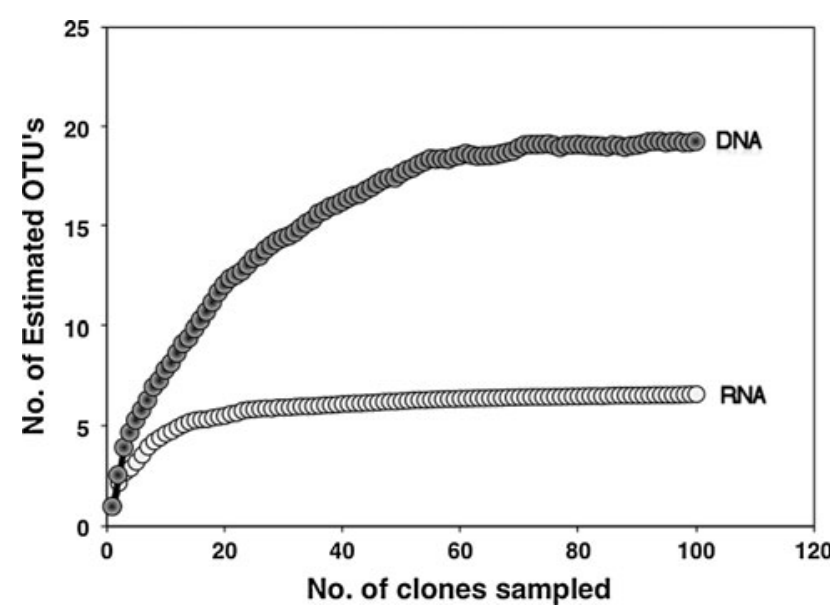

Fig. 2 Rarefaction curve for DNA and RNA (cDNA) ITS clone libraries

Phylogenetic analyses of these environmental phylotypes and cultivated strains revealed that all Zalerion-like DNA and RNA phylotypes plus the cultivated strains likely belonged to a group of closely related Z. varium species (Fig. 3). The Helicodendron- and Lambertella-like phylotypes informed from BLAST searches resolved unambiguously into the Helicodendron/Lambertella lineage within the Helotiales (Fig. 4), yet a lack of sister taxa precluded any firm conclusions about species or teleomorph/anamorph status. The cultivated yeast resolved unambiguously into a cold-tolerant yeast clade with closest affiliation to Debaryomyces hasenii (Fig. 5).

\section{Discussion}

The polyphasic nature of our investigation allowed us to estimate which fungal taxa were recoverable as follows. 
Fig. 3 Phylogenetic

relationships of cultivated Antarctic Zalerion strain, cDNA and DNA phylotypes from clone, respectively, based on ITS region (ITS 5-5.8S rRNA gene-ITS 4). Tree topologies are supported by Bayesian posterior probabilities (first number) and bootstrap values for 1,000 replications (second number). Scale bar, 0.05-nt change per position

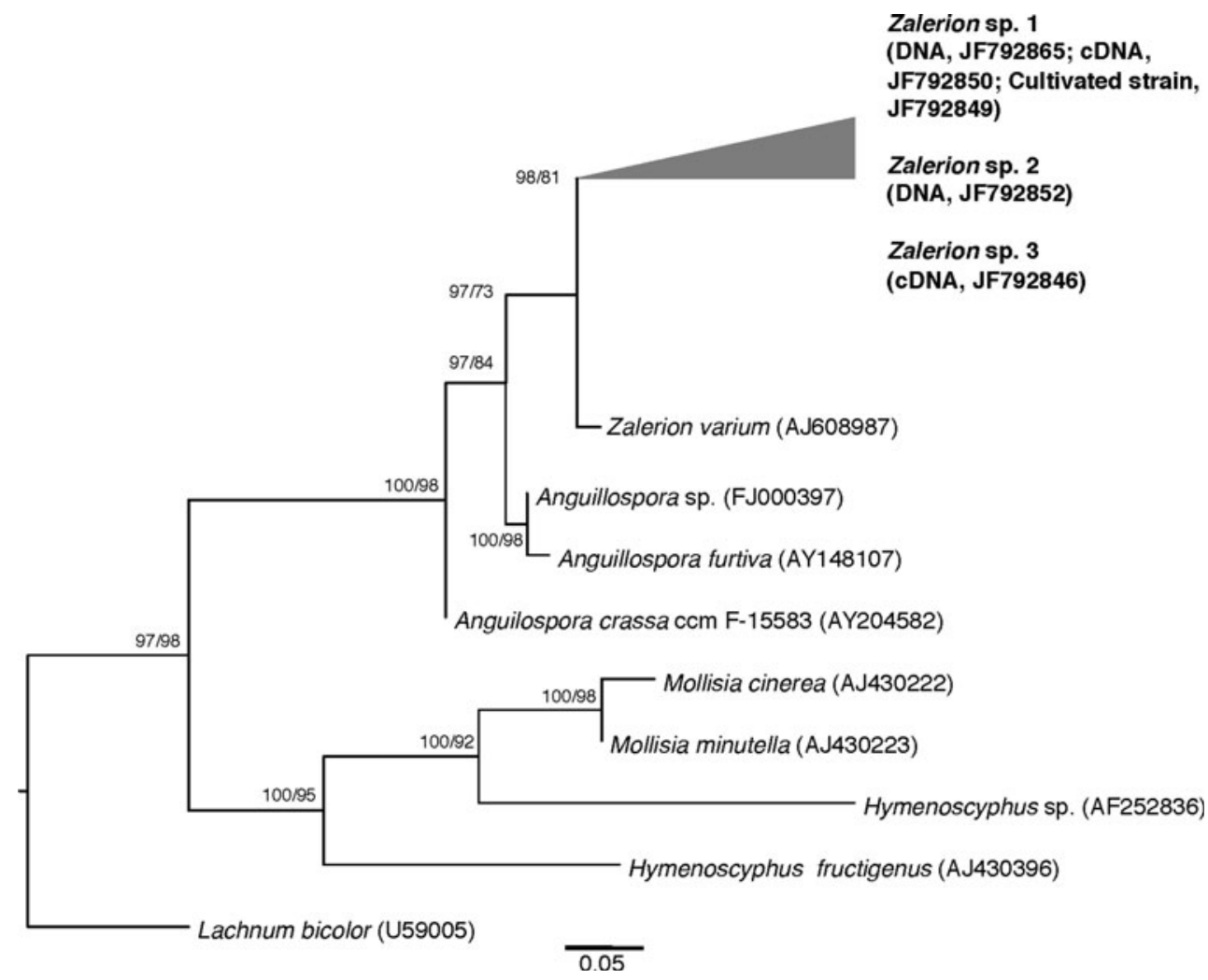

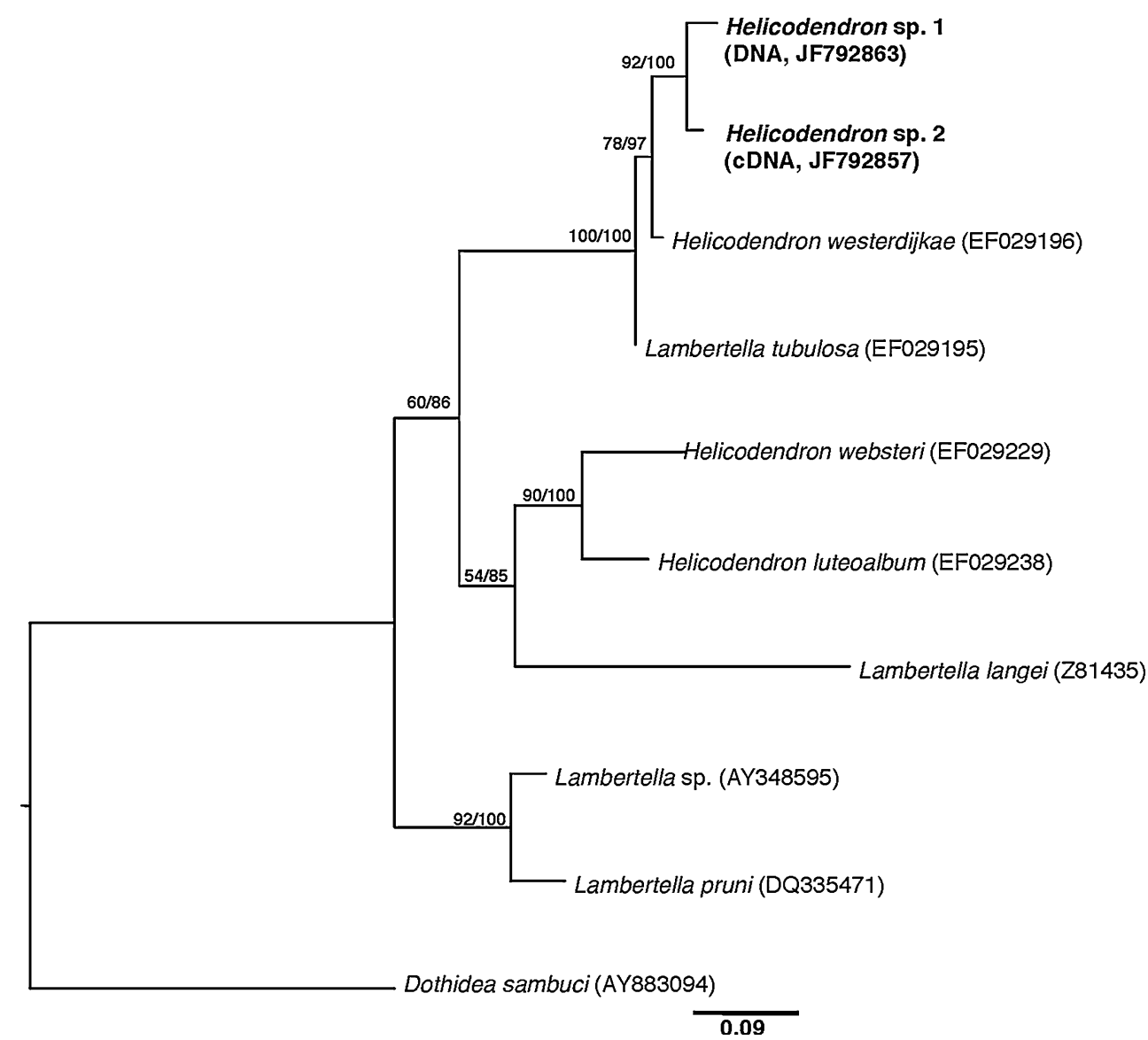

Fig. 4 Phylogenetic relationships of cultivated Antarctic Heliotiales strain, cDNA and DNA phylotypes from clone, respectively, based on ITS region (ITS 5-5.8S rRNA gene-ITS 4). Tree topologies are supported by Bayesian posterior probabilities (first number) and bootstrap values for 1,000 replications (second number). Scale bar, 0.09-nt change per position 
Fig. 5 Phylogenetic relationships of cultivated Antarctic yeast strain and related species based on ITS region (ITS 5-5.8S rRNA geneITS 4). Tree topologies are supported by Bayesian posterior probabilities (first number) and bootstrap values for 1,000 replications (second number). Scale bar, 0.02-nt change per position

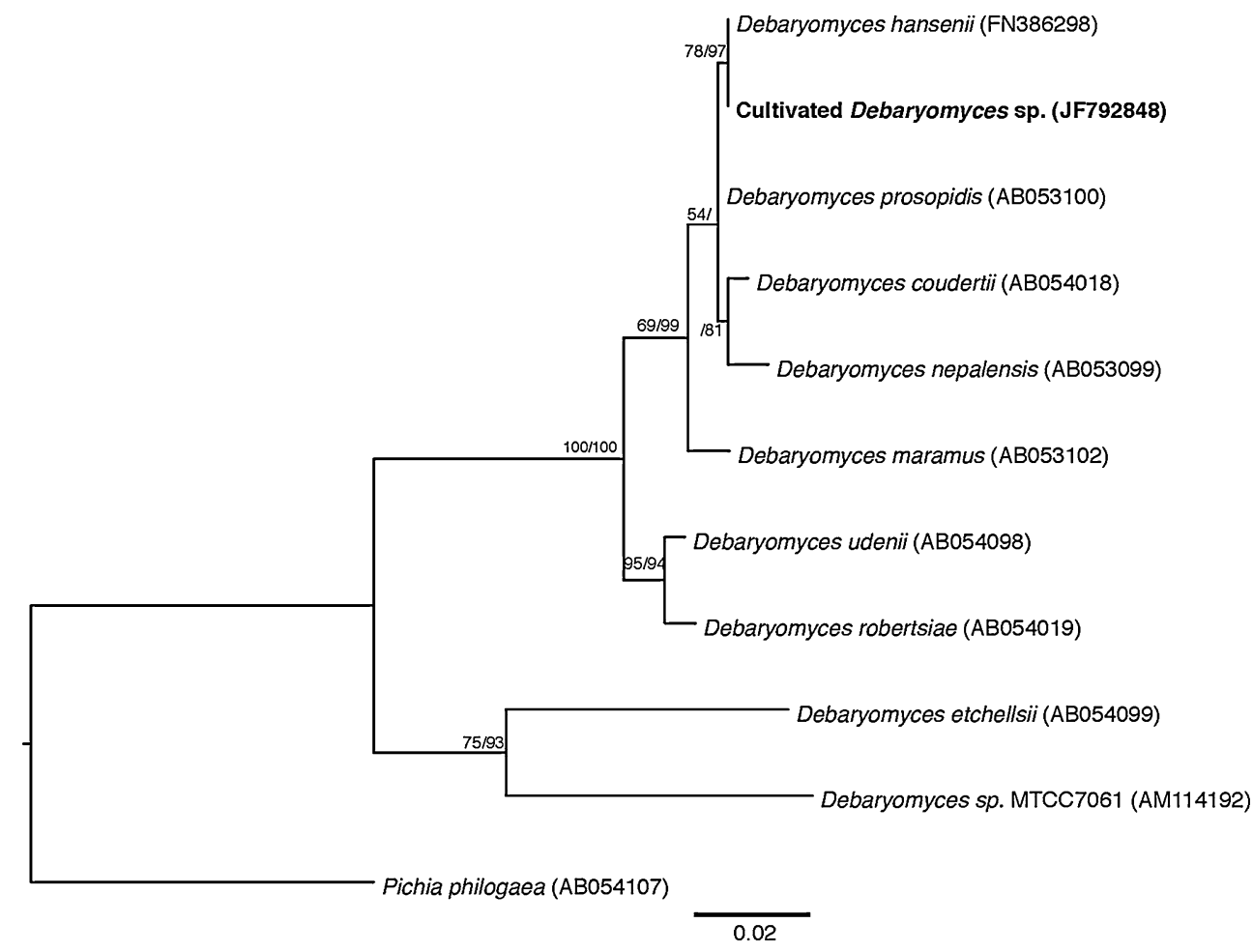

First, DNA signatures indicating the overall fungal presence including resting structures; second, RNA signatures that putatively indicated metabolically active taxa; and third, fungi cultivable under laboratory conditions. This approach provided empirical evidence as to whether DNA signatures are appropriate indicators of active fungal assemblages in permanently cold environments, and the potential confounding effects of legacy or resting structure (e.g., spores) DNA.

Free-living fungi in the Antarctic Dry Valleys are known from only a few descriptions, and phylogenetic analyses are scarce and restricted to maritime Antarctic soils (e.g., Malosso et al. 2006). The highly restricted assemblage recovered in our study was dominated by Zalerion taxa, and this appears a unique feature of our site when compared to other studies of Dry Valleys locations. This filamentous ascomycetous taxon is known largely from descriptions of marine substrates (Hyde et al. 2000). This may indicate that a degree of tolerance to saline conditions is a selective advantage to fungi in these higher valleys where soils may be appreciably saline due to longterm salt accumulation as a result of sublimative water loss from soils (Doran et al. 2002). Further traits of this genus that may be speculated to facilitate Antarctic colonization include strongly pigmented hyphae implicated in UV protection and the ability to grow in low-energy environments (e.g., substrates such as wood and sand in non-polar locations) where nutrients are limited. We observed that the cultivated Antarctic strain grew on growth medium supplemented with up to $3 \% \mathrm{w} / \mathrm{v} \mathrm{NaCl}\left(4-20^{\circ} \mathrm{C}\right)$ but growth rates were reduced compared to non-saline media. It is not possible to identify whether the Zalerion phylotypes represented different ecotypes adapted to specific micro-niches, although the recovery of closely related phylotypes within a species does appear common in other studies of extreme environments (Pointing et al. 2009; Bahl et al. 2011). The recovery of Zalerion species is not a new record for Antarctica, having previously been isolated from maritime soils (Vishniac 1993).

The other filamentous ascomycetous phylotypes appears to be a new record and indicated the presence of Helicodendron species, part of a largely saprophytic family of brightly pigmented fungi. This includes the only described 'endemic' Antarctic fungal genus, Cadophora, isolated from historic wooden huts on Ross Island (Arenz et al. 2006). The ascomycetous yeast Debaromyces hansenii recovered by cultivation in our study is a known cryotolerant and halo-tolerant taxon, often associated with food spoilage (Kreger-van Rij 1984; Prista et al. 2005). Both ascomycetous and basidomycetous yeasts are commonly recovered in cultivation and molecular studies of cold soils, including in Antarctica (e.g., Arenz et al. 2006; Malosso et al. 2006; Singh et al. 2006; Bridge and Newsham 2009). The yeasts may emerge as a physiological group that are particularly well adapted to Antarctic soils, although a systematic landscape-scale survey is needed to test this hypothesis. Studies have indicated that fungi may generally be physiologically more tolerant of freeze-thaw cycles in 
soil than prokaryotes (Sharma et al. 2006; Yergeau and Koalchuk 2008). A point of interest was that approximately half of fungal phylotypes recovered from the RNA-derived library did not display close phylogenetic affiliation with any known fungus. This suggests that a number of as-yet undescribed fungi play a key role in carbon turnover within cold desert soils such as these.

The soil sample in our study was geochemically very similar to other soil samples analyzed from this valley (Pointing et al. 2009) and supported lower carbon levels than other sites where free-living fungi have been isolated with greater species richness (Arenz et al. 2006). This may imply that substrate availability is limiting diversity. A further factor may be that the relatively nutrient-rich status of the cultivation conditions may have biased against taxa adapted to extreme oligotrophy of Dry Valleys soils and this may explain, at least in part, the recovery of relatively few fungal taxa.

The main discrepancy between cultivation and DNA/ RNA estimates in our study was in the recovery of yeasts. We demonstrated that cultivated yeasts could be PCRamplified with the primers used, but failed to detect them in PCR analysis of environmental DNA. This concurs with the findings of Arenz et al. (2006), where this taxon was also only recoverable by cultivation. While several explanations are possible, this might reflect inherently low abundance of this yeast in soil as compared to other yeasts and filamentous fungi. Further experimentation outside the scope of the present study is necessary to confirm or refute this. A comparison of diversity estimates using environmental DNA and RNA (cDNA) indicates that while indices such as species richness may not vary greatly, others that track beta diversity such as Shannon's Diversity Index and evenness estimates may yield different values. Even more striking is the fact that environmental RNA suggests that different taxa may be metabolically active and be present in different abundance than DNA libraries indicate. This is particularly intriguing for the Helicodendron phylotypes, since BLAST matches suggest that the two phylotypes may represent anamorph and teleomorph states of the same fungus, although phylogenetic analysis was insufficient to confirm this. This requires accepting the assumption that rRNA is not recoverable from inactive or resting structures, or as cell-free legacy biosignatures in soil. The lack of recovery of other fungal phylotypes, even in low abundance, suggests that cryopreservation of DNA from inactive and/or dead fungi is at levels that are undetectable using conventional molecular ecological tools. A deepsequencing approach would allow this issue to be resolved with more confidence. We cannot discount bias introduced due to PCR reaction chemistry and cloning bias, although the most significant caveat to our findings probably relates to definition of O.T.U and assigning their identity. The number of base changes that separated sequences was an order of magnitude greater than that expected from sequencing error, but it cannot be proven that each taxon as delineated by $<97 \%$ sequence homology and phylogenetic analysis represents an individual fungus, or variants from a single species. It is also not possible to conclude from our findings which taxa were metabolically the most active, since rRNA gene copy number cannot be directly correlated with catabolic or anabolic metabolic activity, and activity may not be directly related to levels of biomass.

Our study raises some interesting ecological questions that warrant further investigation: Since endolithic and lake biofilms that are recognized as local reservoirs of inoculum do not support the fungi recovered in our study (Pointing et al. 2009), what is the source of inoculum for soil fungi such as Zalerion sp. to the inland Dry Valleys? Why were no common molds recovered such as those observed by Arenz et al. (2006) and was this in part a reflection of selective pressures due to soil chemistry and climate at our extreme inland location? What is the ecological role of fungi, are they important agents of carbon turnover on a landscape scale? and what is the extinction threat to these unique assemblages as climate changes on this continent?

Acknowledgments The research was supported by the Hong Kong Research Grants Council (Grant numbers HKU7733/08 M, HKU7763/10). The authors wish to acknowledge the excellent logistic and field support provided by Antarctica New Zealand (Event K021B). K.D. Hyde thanks the Global Research Network for Fungal Biology and King Saud University for support.

Open Access This article is distributed under the terms of the Creative Commons Attribution Noncommercial License which permits any noncommercial use, distribution, and reproduction in any medium, provided the original author(s) and source are credited.

\section{References}

Arenz BE, Held BW, Jurgens JA, Farrell RL, Blanchette RA (2006) Fungal diversity in soils and historic wood from the Ross sea region of Antarctica. Soil Biol Biochem 38:3057-3064

Bahl J, Lau MCY, Smith GJD, Vijaykrishna D, Cary SC, Lacap DC, Lee CK, Papke TR, Warren-Rhodes KA, Wong FKY, McKay CP, Pointing SB (2011) Ancient origins determine global biogeography of hot and cold desert cyanobacteria. Nat Commun 2:163. doi: $10.1038 /$ ncomms 1167

Bridge PD, Newsham KK (2009) Soil fungal community composition at Mars Oasis, a southern maritime Antarctic site. Fungal Ecol 2:66-74

Cary SC, McDonald IR, Barrett JE, Cowan DA (2010) On the rocks: the microbiology of Antarctic Dry Valley soils. Nat Rev Microbiol 8:29-138

Convey P, Stevens MI, Hodgson DA, Smellie JL, Hillenbrand CD, Barnes DK, Clarke A, Pugh PJ, Linse K, Cary SC (2009) Exploring biological constraints on the glacial history of Antarctica. Quat Sci Rev 28:3035-3048 
Cowell RK (2005) EstimateS: statistical estimation of species richness and shared species from samples. Version 7.7. Available at http://www.purl.oclc.org/estimates. Accessed January 7, 2009

Doran PT et al (2002) Antarctic climate cooling and terrestrial ecosystem response. Nature 415:517-520

Friedmann EI (1982) Endolithic microorganisms in the Antarctic cold desert. Science 215:1045-1053

Gerday CM et al (1997) Psychrophilic enzymes: a thermodynamic challenge. Biochim Biophys Acta 1342:119-131

Hyde KD, Sarma VV, Jones EBG (2000) Morphology and taxonomy of higher marine fungi. In: Hyde KD, Pointing SB (eds) Marine mycology - a practical approach. Fungal Diversity Research Series, vol 1, pp 172-204

Kreger-van Rij NJW (1984) The yeasts, a taxometric study. Elsevier, Amsterdam

Malosso E, Waite IS, English L, Hopkins DW, O’Donnell AG (2006) Fungal diversity in maritime Antarctic soil determined using a combination of culture isolation, molecular fingerprinting and cloning techniques. Polar Biol 29:552-561

Onofri S, Selbmann L, Zucconi L, Pagano S (2004) Antarctic microfungi as models for exobiology. Planet Space Sci 52:229-237

Pointing SB, Chan Y, Lacap DC, Lau MCY, Jurgens JA, Farrell RL (2009) Highly specialized microbial diversity in hyper-arid polar desert. Proc Natl Acad Sci USA 106:19964-19969

Prista C, Loureiro-Dias MC, Montiel V, Garcia R, Ramos J (2005) Mechanism underlying the halotolerant way of Debaryomyces hansenii. FEMS Yeast Res 5:693-701

Schloss PD, Handelsman J (2005) Introducing DOTUR, a computer program for defining operational taxonomic units and estimating species richness. App Environ Microbiol 71:1501-1506
Sharma S, Szele Z, Schilling R, Munch JC, Schloter M (2006) Influence of freeze-thaw stress on the structure and function of microbial communities and denitrifying populations. App Environ Microbial 72:2148-2154

Singh SM, Puja G, Bhat DJ (2006) Pscychrophilic fungi from Schirmacher Oasis, East Antarctica. Curr Sci 90:1388-1392

Swofford DL (2001) PAUP*: phylogenetic analysis using parsimony (*and other methods) Version 4.0b8. Sinauer, Sunderland

Thompson JD, Gibson TJ, Plewniak F, Jeanmougin F, Higgins DG (1997) The Clustal X Windows interface: flexible strategies for multiple sequence alignment aided by quality analysis tools. Nucl Acids Res 24:4876-4882

Vishniac HS (1993) The microbiology of Antarctic soils. In: Friedmann EI (ed) Antarctic microbiology. Wiley-Liss, New York, pp 297-341

Vishniac HS (1996) Biodiversity of yeasts and filamentous microfungi in terrestrial Antarctic ecosystems. Biodivers Conserv 5:1365-1378

White TJ, Bruns TD, Lee S, Taylor J (1990) Analysis of phylogenetic relationships by amplification and direct sequencing of ribosomal RNA genes. In: Innis MA, Gelfand DH, Sninsky JJ, White TJ (eds) PCR protocols: a guide to methods and applications. Academic Press, New York, pp 315-322

Wynn-Wiliams DD (1990) Ecological aspects of Antarctic microbiology. Adv Microbial Ecol 11:71-146

Yergeau E, Koalchuk GA (2008) Responses of Antarctic soil microbial communities and associated functions to temparature and freeze-thaw cycle frequency. Environ Microbiol 10:22232235 